\title{
Sustainability SI: Multimode Multicommodity Network Design Model for Intermodal Freight Transportation with Transfer and Emission Costs
}

\author{
Yi Qu · Tolga Bektaş · Julia Bennell
}

Received: date / Accepted: date

\begin{abstract}
Intermodal freight transportation is concerned with shipping of commodities from their origin to destination using combinations of transport modes. Traditional logistics models have concentrated on minimizing transportation costs by appropriately determining the service network and the transportation routing. This paper considers an intermodal transportation problem with an explicit consideration of greenhouse gas emissions and intermodal transfers. A model is described which is in the form of a non-linear integer programming formulation, which is then linearized. A hypothetical but realistic case study of the UK including eleven locations forms the test instances for our investigation, where uni-modal with multi-modal transportation options are compared using a range of fixed costs.
\end{abstract}

Keywords Intermodal transportation · Service network design · Greenhouse gas emission $\cdot$ Intermodal transfer cost

Yi Qu

Southampton Management School, CORMSIS, University of Southampton, Southampton, SO17 1BJ, United Kingdom

Tel.: +44 (0) 2380598969

Fax: +44 (0) 2380593844

E-mail: Y.Qu@soton.ac.uk

Tolga Bektaş (Corresponding author)

Southampton Management School, CORMSIS, University of Southampton, Southampton, SO17 1BJ, United Kingdom

E-mail: T.Bektas@soton.ac.uk

Julia Bennell

Southampton Management School, CORMSIS, University of Southampton, Southampton, SO17 1BJ, United Kingdom

E-mail: J.A.Bennell@soton.ac.uk 


\section{Introduction}

The transportation industry is rapidly changing due to technological advances and the constant need to find faster and cheaper ways to transport freight across the globe. Intermodal freight transport is a system for transporting goods, particularly over longer distances and across international borders, which has played a significant role in the freight transportation industry. An intermodal freight transportation system includes ocean and coastal routes, inland waterways, railways, roads, and airways. Intermodal transportation is the shipment of commodities from one point to another using combinations of at least two different transport modes (e.g., truck to train to barge to oceangoing vessel) (Bektaş and Crainic, 2007).

The volume of freight transport has grown rapidly in the last four decades. In 1971, the domestic freight market totalled just 134 billion tonne-kilometres, while by 2010 it has expanded to more than 220 billion tonne-kilometres (Department for Transport, 2012). Increasing freight transportation brings with it concerns about air quality and climate change. Freight transportation is largely driven by fossil fuel combustion, mostly diesel fuel, resulting in emissions of greenhouse gases $(\mathrm{GHG})$, such as Carbon dioxide $\left(\mathrm{CO}_{2}\right)$, Nitrogen oxide $\left(\mathrm{NO}_{\mathrm{X}}\right)$, Sulfur oxide $\left(\mathrm{SO}_{\mathrm{X}}\right)$, particulate matters and air toxics.

GHG emissions not only are harmful to the health of humans, but also have harmful impacts on environment, including the increased drought, more heavy downpours and flooding, greater sea level rise and harm to water resources, agriculture, wildlife and ecosystems. Global emissions of $\mathrm{CO}_{2}$ as the primary GHG increased by $3 \%$ in 2011, reaching an all-time high of 34 billion tonnes in 2011 (Oliver et al, 2012). In the UK, the total GHG emissions from transport have increased by $13 \%$ between 1990 and 2009. The proportion of total UK GHG emissions from transport have increased from $18 \%$ in 1990 to $27 \%$ in 2009 (Department for Transport, 2011). In 2009, the freight transport within the UK is estimated to account for $21 \%$ of domestic transport GHG emissions and $5 \%$ of all UK domestic GHG emissions (Department for Transport, 2011).

Traditional logistics models have concentrated on minimizing operational transportation costs. But the consideration of the wider objectives and issues especially related to GHG emissions leads to new models and technologies. In this paper, an intermodal transportation problem is described that includes consideration of GHG emissions, in which $\mathrm{CO}_{2}$ emissions are explicitly modelled. In our model, the objective is to minimize the total costs in an intermodal system, including the capital costs, operational costs, intermodal transfer cost and the GHG emissions cost, such that a number of commodities are shipped from their origin to destination. The decisions to be made comprise: (i) the selection of routes and transport modes and (ii) the flow distribution through the selected route and mode. The resulting green service network design model is a non-linear mixed integer program. We propose a linearization to transform the model into an integer linear programming formulation which is then solved by off-the-shelf optimization software. 
The key contributions of this paper can be summarized as follows: (i) We present a model which, to the best of our knowledge, is the first to explicitly include intermodal transfer cost in its objective when modeling a green intermodal transportation system. (ii) we present the results of a hypothetical but realistic numerical study based on data collected from the UK.

The rest of the paper is organized as follows: In the following section, a brief literature review is presented. Section 3 discusses a way of estimating emissions and presents a non-linear service network design model with intermodal transfer cost, which is then linearized. In Section 4, a hypothetical case study from the UK is provided and results of computational experiment and analyses are presented. The paper concludes in Section 5.

\section{A Brief Review of the Literature}

An informative overview on intermodal transport is given in Bektaş and Crainic (2007) and Crainic and Kim (2007). A general description of current issues and challenges related to the large-scale implementation of intermodal transportation systems in the United States and Europe is presented by Zografos and Regan (2004). A large body of mathematical solutions, mostly operational research models and methods, have been applied to generate and evaluate the transportation network. Macharis and Bontekoning (2004), and Janic and Bontekoning (2002) present the opportunities for operational research in the intermodal transportation research application field. They have concluded that modeling intermodal freight transport is more complex than modeling uni-modal systems. They also define the problems and review the associated mathematical models that are currently in use in this field. However, their overview covers publications only up to 2002 . In recent 10 years, a significant number of papers on this topic have appeared. For example, Meng and Wang (2011) proposed a mathematical formulation to design an intermodal huband-spoke network for multi-type container transportation, which is suitable when there are multiple stakeholders such as the network planner, carriers, hub operators, and intermodal operators. Arnold et al (2004) presented a systematic approach to deal with the problem of optimally locating the rail/road terminals for freight transports in relation to the cost criterion. The problem is solved using a heuristic approach involving the solution of a shortest path problem for each commodity. Yamada et al (2009) presented a bi-level programming model for strategic, discrete freight transportation network design, in which the genetic local search mothod is suggested to find near-optimal actions to maximise the freight-related benefit-cost ratio depending on their impact on freight and passenger flows. The model is applied to an actual interregional intermodal freight transport network in Philippines. The above three models do not consider the external costs associated with the logistics and transportation network.

According to Crainic and Laporte (1997), decision makers in transportation are faced with planning problems of three different time horizons, namely 
strategic, tactical and operational level of planning. Strategic planning (long term) involves the highest level of management. Decisions at this planning level affect the design of the physical infrastructure network, see Steenbrink (1974), Magnanti and Wong (1984), Crainic and Rousseau (1986) and surveys in Campbell et al (2002) and Ebery et al (2000). Tactical planning (medium term) helps improving the performance of the whole intermodal transportation system by ensuring an efficient allocation of existing resources over a medium term horizon, see Crainic and Kim (2007) and Crainic and Laporte (1997). Operational planning (short term) is performed by local management, at which level, day-to-day decisions are made in a highly dynamic environment where the time factor plays an important role, see Crainic and Laporte (1997), Christiansen et al (2007) and Crainic and Kim (2007).

The service network design problem is a key tactical problem in intermodal transport, which is also the case in our paper. Service network design formulations are generally used to determine the routes on which service will be offered, the type of service, as well as the frequency of the schedule of each route Crainic (2000). The performance of the service network design model is evaluated by the tradeoffs between total operating costs and service quality. In solving freight transportation network design problems, much effort has been dedicated to the variant of the problem where there are no limitations on the transportation capacity and significant results have been obtained. Balakrishnan et al (1989) have presented a dual-ascent procedure for large-scale uncapacitated network design that very quickly achieves lower bounds within 1-4\% of optimality. Later research has focused on the capacitated service network design problem to capture more realistic settings. Holmberg and Yuan (2000) formulate a general model for capacitated multi-commodity network design and propose its Lagrangian heuristic algorithm. A recent and up-todate review of service network design problem, we refer the reader to Crainic and Kim (2007) and Crainic and Laporte (1997).

Service network design models are extensively used to solve a wide range of tactical planning and operations problems in transportation, logistic and telecommunications systems. For example, Ben-Ayed et al (1992) describe a formulation of the highway network design problem as a bi-level linear program for optimizing the investment in the inter-regional highway network. They then apply this model to the Tunisian network using actual data. Kuby et al (2001) present a spatial decision support system for network design problems in which different kinds of projects can be built in stages over time and apply this model to the Chinese railway network. They also introduce some easyto-implement innovations to reduce the size of the problem to be solved by branch-and-bound.

Winebrake et al (2008b) present a geospatial intermodal freight transport model to help analyse the cost, time-of-delivery, energy, and environmental impacts of intermodal freight transport. Three case studies are also applied to exercise the model. However, they use single criterion objective functions (such as minimizing cost, or time or $\mathrm{CO}_{2}$ ), which provide the extreme values across the different criteria. We break away from this research by modeling the 
emissions and transfers as external costs in our model. Moreover, Winebrake et al (2008b) only consider a single origin-destination commodity. In contrast, we test several commodities in our model for a more systematic analysis.

Bauer et al (2009) are the first to explicitly consider GHG emissions as a primary objective and propose a linear cost, multi-commodity, capacitated network design formulation to minimize the amount of GHG emissions of intermodal transportation activities. They also apply this model in a real-life rail freight service network design and present the tradeoffs between conflicting objectives of minimizing time-related and environmental costs. Our model differs from Bauer et al (2009) in the objective function. We minimize the total transportation costs, including the operating cost, fixed cost, GHG emission cost and intermodal transfer cost.

One other often ignored aspect when modeling intermodal transportation problems is the terminals where classification operations are carried out. As pointed out by Bektaş and Crainic (2007), terminals are "perhaps the most critical components of the entire intermodal transportation chain", and "the efficiency of the latter highly depends on the speed and reliability of the operations performed in the former". This is therefore important to capture terminal operations in a modeling framework. However, it is difficult to explicitly model speed and reliability of terminal operations at a tactical level, as these meaesures require a treatment at an operational level. To overcome the difficulty, in this model we capture this phenomenon by using transfer cost.

\section{Problem Description and Mathematical modeling}

\subsection{Estimating Emissions}

There are several approaches for estimating the GHG emissions including an energy-based approach and an activity-based approach. For a review of several vehicle emission models, we refer the reader to Demir et al (2011). Most of the models presented therein are of microscopic nature. For our modeling approach which is at a more strategic/tactical level of planning, we have opted to use an activity-based function by McKinnon and Piecyk (2010) to estimate $\mathrm{CO}_{2}$ emissions in intermodal transportation. This approach is also commonly used, e.g., Treitl et al (2012) use it to estimate the total transport emissions in a petrochemical distribution network in Europe, and Park et al (2012) use it to calculate $\mathrm{CO}_{2}$ emissions in a road network for trucks and railway in intermodal freight transportation in Korea.

According to McKinnon and Piecyk (2010), the total cost of $\mathrm{CO}_{2}$ emissions of a vehicle carrying a load of $l$ (in tonnes) over a distance of $d$ (in $\mathrm{km}$ ) calculated by equation (1) below,

$$
l \times d \times e
$$

where $e$ is the average $\mathrm{CO}_{2}$ emission factor $\left(\mathrm{g} /\right.$ tonne-km). To convert $\mathrm{CO}_{2}$ emissions into monetary units, we adopt the figures provided by the World 
Bank (The World Bank, 2012), in particular we use $\$ 100$ per ton $(=£ 71.6$ per tonne).

The rationale for adopting this $\mathrm{CO}_{2}$ emissions function is in its ease of use. First, it has the advantages of including variables to measure the total freight weight as well as the corresponding distance transported, while avoiding the elements that are hard to measure or calculate, such as different vehicle and fuel types for each mode of transport. Second, it is applicable to different transportation modes. For a given mode of transportation, the total $\mathrm{CO}_{2}$ emissions are dependent on the shipping distance and the weight of the commodities shipped.

\subsection{Problem Description}

The problem is defined on a network, represented by a set of nodes $N$, a set of links $A$ connecting these nodes, a set of transportation modes $M$ and a set of commodities $K$. The traffic flows between the nodes can be expressed in terms of an origin-destination flow matrix. Each vehicle of a given mode has a load capacity when running on a particular link. The total transportation cost results from a vehicle moving over a link, including variable and fixed costs. The variable cost per weight unit of commodities is the transportation cost, which covers the carrier's fuel costs, crew costs, overhead costs and administration costs. We assume that variable transportation cost is constant over time and that they depend only on the link. The fixed cost consists primarily of operators' wages and handling costs incurred for moving commodities on and off the vehicles. We assume that each vehicle of the same mode of transport incurs the same fixed cost. Intermodal transfer cost arises from transferring freight from one transportation mode to another in an intermodal yard (e.g., port and rail yard). In our modeling, we assume that transfer cost does not depend on the combinations of nodes involved in the transfer. While this might be seen as a strong assumption, there are two reasons why we do so. First, the literature on intermodal transportation modeling states that the internal handling costs are only depend on the load, e.g., Janic (2007) and Winebrake et al (2008b) The only case that different combinations of modes for a transfer result in different values is external costs (of emissions) although they do not vary significantly (Winebrake et al, 2008b). The second reason is that, an explicit consideration of combination of modes in a transfer will require a different model, possibly with more variables, to represent the possible combinations. However, the number of such combinations might be large. For example, in instance with $|M|=4$, there are six possible combinations, whereas if the number of modes increases to 10 , there could be up to 45 different combinations. Given the figures obtained from the literature, and to simplify the representation, the unit handling cost at terminals is assumed to be fixed. An alternative model which distinguishes between transfer cost would be worth exploring in future research. 


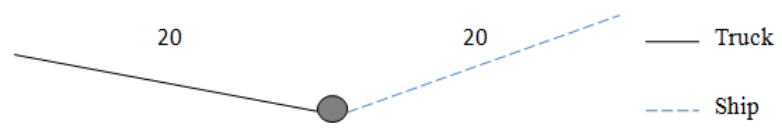

Fig. 1 Example 1 for how transfer cost occurred at intermodal node

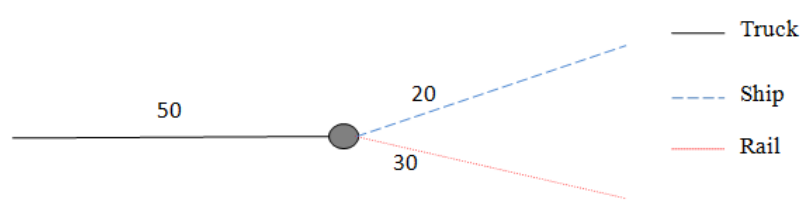

Fig. 2 Example 2 for how transfer cost occurred at intermodal node

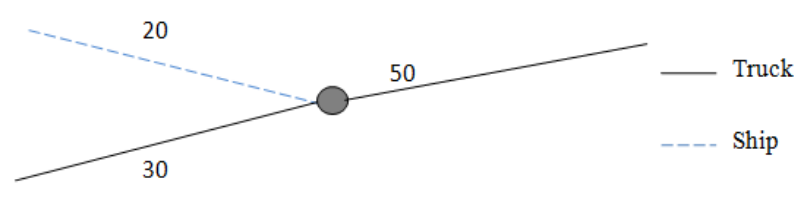

Fig. 3 Example 3 for how transfer cost occurred at intermodal node

The problem considered in this paper is to "design" the network by assigning a number of vehicles to links and ship commodities from their origin to destination by respecting constraints on the link capacities, flows and requirements for demands. The overall objective is to minimize a total cost function, including variable costs, fixed costs, emission cost and transfer cost.

We present three examples in Figure 1-3 showing how transfer occurs at an intermodal node. In Figure 1, 20 units of a commodity are transported by truck at first. When they reach an intermodal node, the transportation mode is changed to ship, so there is one transfer occurring. In Figure 2, 50 units of the commodity are transported to the intermodal mode by truck and they are split into two parts, 20 units are shipped by ship and 30 units are shipped by rail. There are two transfers occurring at this node for this commodity. In Figure 3, the commodity is brought into the terminal by ship and truck. One transfer occurs at the node. The transportation mode for the 20 units is then changed to truck.

\subsection{Mathematical modeling}

To formulate the green service network design problem described in the previous section as a mathematical programming formulation, we define the notation as shown in Table 1. 
Table 1 Mathematical notation and the explanation in our model

\begin{tabular}{ll}
\hline Notation & Explanation \\
\hline$G=(N, A)$ & Transportation network, where $N$ corresponds to the set of nodes and \\
& $A$ represent the set of arcs \\
$N_{i}^{+}=\{j \in N:(i, j) \in A\}$ & The set of outward neighbors for each node \\
$N_{i}^{-}=\{j \in N:(j, i) \in A\}$ & The set of inward neighbors for each node \\
$b_{i}^{k}$ & The difference amount for commodity $k \in K$ between coming out of \\
& and coming into node $i \in N$ \\
$c_{i j}^{m}$ & Unit variable costs for shipping commodities on arc $(i, j) \in A$ by mode \\
& $m \in M$ \\
$d_{(k)}$ & The destination of commodity $k \in K$ \\
$d_{i j}^{m}$ & Distance of arc $(i, j) \in A$ by mode $m \in M$ \\
$f_{i j}^{m}$ & Unit fixed costs for shipping commodities on arc $(i, j) \in A$ by mode \\
& $m \in M$ \\
$h_{i}^{k}$ & The absolute value of $b_{i}^{k}$ \\
$l_{i j}^{k m}$ & Function of minimum flow of commodity $k \in K$ on arc $(i, j) \in A$ by \\
$o(k)$ & mode $m \in M$ \\
$p^{m}$ & The origin of commodity $k \in K$ \\
$r^{k}$ & Cost of emissions for mode $m \in M$ \\
$u_{i j}^{m}$ & The quantity of commodity $k \in K$ that is to be sent from o( $k)$ to $d(k)$ \\
$w$ & The maximum capacity for arc $(i, j) \in A$ by mode $m \in M$ \\
$x_{i j}^{k m}$ & The unit transfer cost for commodities \\
$y_{i j}^{m}$ & Flow variable for commodity $k \in K$ on arc $(i, j) \in A$ by mode $m \in M$ \\
& Number of vehicles transported on arc $(i, j) \in A$ by mode $m \in M$ \\
&
\end{tabular}

Using the notation in Table 1, a mathematical model for the problem can be written as follows:

$$
\begin{gathered}
\text { Minimize } \sum_{k \in K} \sum_{(i, j) \in A} \sum_{m \in M} c_{i j}^{m} x_{i j}^{k m} \\
+\sum_{(i, j) \in A} \sum_{m \in M} f_{i j}^{m} y_{i j}^{m} \\
+\sum_{k \in K} \sum_{(i, j) \in A} \sum_{m \in M} d_{i j}^{m} p^{m} x_{i j}^{k m} \\
+\frac{1}{2} w \sum_{i \in N} \sum_{k \in K}\left(\sum_{m \in M}\left|\sum_{j \in N_{j}^{+}} x_{i j}^{k m}-\sum_{j \in N_{j}^{-}} x_{j i}^{k m}\right|-h_{i}^{k}\right)
\end{gathered}
$$

subject to

$$
\begin{gathered}
\sum_{j \in N_{j}^{+}} \sum_{m \in M} x_{i j}^{k m}-\sum_{j \in N_{j}^{-}} \sum_{m \in M} x_{j i}^{k m}=b_{i}^{k} \quad \forall i \in N, \forall k \in K \\
\sum_{k \in K} x_{i j}^{k m} \leq u_{i j}^{m} y_{i j}^{m} \quad \forall(i, j) \in A, \forall m \in M \\
x_{i j}^{k m} \geq 0 \quad \forall(i, j) \in A, \forall k \in K, \forall m \in M
\end{gathered}
$$




$$
y_{i j}^{m} \in\{0,1,2 \ldots\} \quad \forall(i, j) \in A, \quad \forall m \in M .
$$

In this model,

$$
b_{i}^{k}=\left\{\begin{array}{c}
r^{k}, i=o(k) \\
-r^{k}, i=d(k) \\
0, \text { otherwise }
\end{array}\right.
$$

and

$$
h_{i}^{k}=\left\{\begin{array}{c}
r^{k}, i=o(k) \text { or } i=d(k) \\
0, \text { otherwise. }
\end{array}\right.
$$

The model (2)-(11) presented above is a non-linear, multi-commodity multimodal service network design formulation. The objective function measures the total transportation costs. Components (2), (3), (4) and (5) are variable costs, fixed costs, the emission cost and the intermodal transfer cost, respectively.

A bundle of flow conservation constraints is shown by equation (6), which also expresses the demand requirements. In this case, each commodity has only one origin and one destination. Constraint set (7) introduces the capacity constraints. Constraint set (8) guarantees that the total flow on arc $(i, j)$ using mode $m \in M$ must not exceed the product of the capacity of each vehicle and the number of vehicles used of mode $m \in M$. If the arc $(i, j)$ is not chosen in the shipping network or the mode $m \in M$ is not used on arc $(i, j)$ (i.e., $\left.y_{i j}^{m}=0\right)$, the flow on arc $(i, j)$ has to be 0 . Constraint sets (8) and (9) are to make sure the decision variables $x_{i j}^{k m}$ for the flow of each commodity flow for each commodity $k \in K$ and $y_{i j}^{m}$ for the number of vehicles of mode $m \in M$ on each link are non-negative and integer, respectively.

The non-linear nature of the model due to the objective function makes it chalenging to solve as it is known that non-linear mixed integer programming models are much more difficult to solve compared to their linear counterparts. To overcome this difficulty, we present a linearization in the next section.

\subsection{Linearization}

The second part of the objective function shown by component (5) is nonlinear, due to the absolute value used to model transfers. To linearize, we use a variable $z_{i}^{k m}$ defined for each $i \in N, k \in K$ and $m \in M$. More specifically, $z_{i}^{k m}$ shows the transferred amount of commodity $k \in K$ by mode $m \in M$ at node $i \in N$ if there is a transfer at this node.

Proposition 1 The component $\left|\sum_{j \in N_{j}^{+}} x_{i j}^{k m}-\sum_{j \in N_{j}^{-}} x_{j i}^{k m}\right|$ for $\forall i \in N, \forall k \in$ $K, \forall m \in M$ can be linearized using the following constraints:

$$
\sum_{j \in N_{j}^{+}} x_{i j}^{k m}-\sum_{j \in N_{j}^{-}} x_{j i}^{k m} \leq z_{i}^{k m}, \forall i \in N, \forall k \in K, \forall m \in M
$$




$$
\sum_{j \in N_{j}^{-}} x_{j i}^{k m}-\sum_{j \in N_{j}^{+}} x_{i j}^{k m} \leq z_{i}^{k m}, \forall i \in N, \forall k \in K, \forall m \in M,
$$

where $z_{i}^{k m}=\left|\sum_{j \in N_{j}^{+}} x_{i j}^{k m}-\sum_{j \in N_{j}^{-}} x_{j i}^{k m}\right|$.

Proof First, notice that $\sum_{j \in N_{j}^{+}} x_{i j}^{k m}-\sum_{j \in N_{j}^{-}} x_{j i}^{k m}=-\left(\sum_{j \in N_{j}^{-}} x_{j i}^{k m}-\sum_{j \in N_{j}^{+}} x_{i j}^{k m}\right)$.

Namely, if $\sum_{j \in N_{j}^{+}} x_{i j}^{k m}-\sum_{j \in N_{j}^{-}} x_{j i}^{k m} \geq 0$, then $\sum_{j \in N_{j}^{-}} x_{j i}^{k m}-\sum_{j \in N_{j}^{+}} x_{i j}^{k m} \leq 0$. If $\sum_{j \in N_{j}^{+}} x_{i j}^{k m}-\sum_{j \in N_{j}^{-}} x_{j i}^{k m}<0$, then $\sum_{j \in N_{j}^{-}} x_{j i}^{k m}-\sum_{j \in N_{j}^{+}} x_{i j}^{k m}>0$.

Now we consider two cases. If $\sum_{j \in N_{j}^{+}} x_{i j}^{k m}-\sum_{j \in N_{j}^{-}} x_{j i}^{k m} \geq 0$, then constraint (12) and the minimizing objective function (2)-(5) will guarantee that $z_{i}^{k m}=\sum_{j \in N_{j}^{+}} x_{i j}^{k m}-\sum_{j \in N_{j}^{-}} x_{j i}^{k m}$. In the other case where $\sum_{j \in N_{j}^{+}} x_{i j}^{k m}-$ $\sum_{j \in N_{j}^{-}} x_{j i}^{k m}<0$, then constraint (13) along with the minimizing objective function (2)-(5) will guarantee $z_{i}^{k m}=\sum_{j \in N_{j}^{-}} x_{j i}^{k m}-\sum_{j \in N_{j}^{+}} x_{i j}^{k m}$.

With the new variable $z_{i}^{k m}$, the formulation can be rewritten as:

$$
\begin{gathered}
\text { Minimize } \sum_{k \in K} \sum_{(i, j) \in A} \sum_{m \in M} c_{i j}^{m} x_{i j}^{k m} \\
+\sum_{(i, j) \in A} \sum_{m \in M} f_{i j}^{m} y_{i j}^{m} \\
+\sum_{k \in K} \sum_{(i, j) \in A} \sum_{m \in M} d_{i j}^{m} p_{m} x_{i j}^{k m} \\
+\frac{1}{2} w \sum_{i \in N} \sum_{k \in K}\left(\sum_{m \in M} z_{i}^{k m}-h_{i}^{k}\right)
\end{gathered}
$$

subject to $(6)-(9),(12),(13)$.

Now our model is a linear mixed integer program, which can be solved using any available optimization software. In the following section, we present results of computational experiments using this linearized formulation on a hypothetical case study from the UK.

\section{Computational Experiments}

\subsection{Description of the Case Study}

To demonstrate the application and guide the further development of our intermodal model, this section presents a hypothetical but realistic UK intermodal transportation case study. The network consists of 11 nodes, of which nine are important ports in the UK, namely Edinburgh, Newcastle, Liverpool, Milford Haven, Bristol, Felixstowe, London, Folkestone and Southampton. Two of the nodes are important inland cities, Birmingham and Manchester. A geographical representation of the nodes in the network is shown in Figure 4. There are 


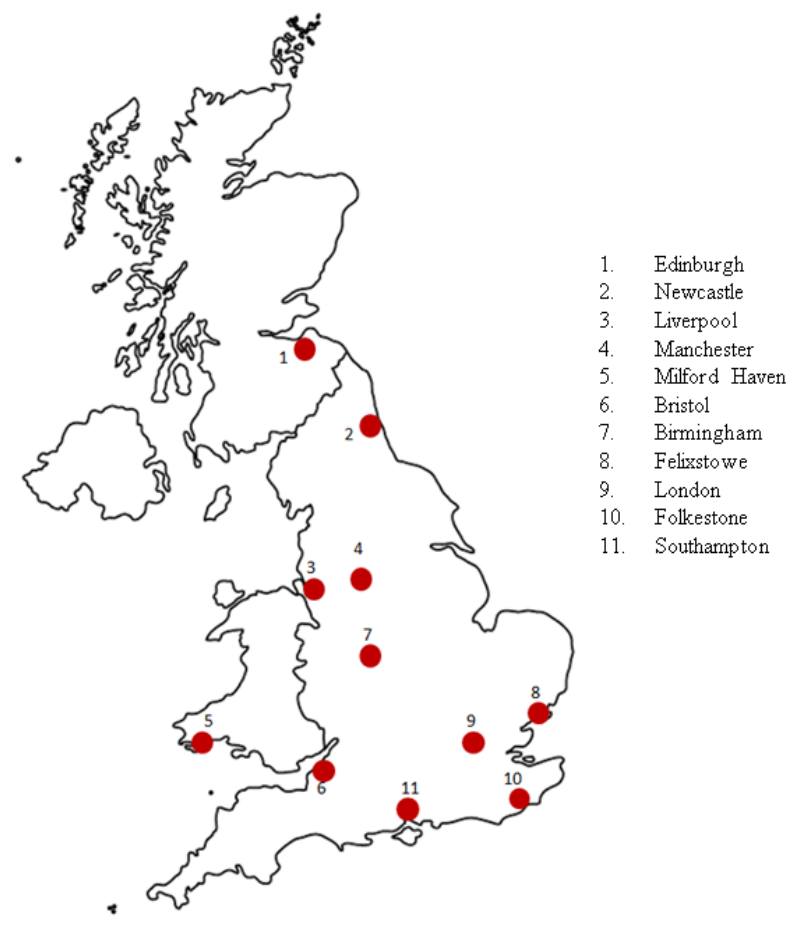

Fig. 411 UK cities and ports in the network

three transportation modes assumed to be running in the network: truck, rail and ship. For Birmingham and Manchester, only rail and truck available, while for other nodes, all transportation modes are available. The service network design case study therefore comprises 292 possible directed arcs between 11 nodes. We consider actual route distance in stead of straight-line distance to make the computational results more realistic. For road and rail journeys, the distance is provided by Travel Footprint Limited (travelfootprint.org), where road distances come from Google Maps using best route road algorithms and will apply to all road vehicles, while for rail, distance is calculated according to main rail line distances using the most common rail interchanges, see Lane (2006). For sea journey, distances between pairs ports are provided by sea-distance.com. There are 30 different commodities to be transported in the network. We randomly generate the origin, destination and demand requirement for each commodity, which is shown in Table 2. The data for capacity, unit variable cost, unit transfer cost and $\mathrm{CO}_{2}$ emissions factor for each mode are found from the literature, see Department for Transport (2005), Andersson et al (2011), Faulkner (2004), Winebrake et al (2008a) and McKinnon and Piecyk (2010), summarized in Table 3. As can be seen from this table, the capacities, variable costs and emissions tend to vary from one mode to another, although the transfer cost is in this instance the same across all modes (Wine- 
Table 2 Origins, destinations and demands for 30 commodities

\begin{tabular}{cccc}
\hline No. & Origin Node & Destination Node & Required demand (tonne) \\
\hline 1 & 5 & 3 & 212 \\
2 & 11 & 9 & 1182 \\
3 & 2 & 11 & 794 \\
4 & 5 & 4 & 128 \\
5 & 2 & 9 & 182 \\
6 & 4 & 6 & 99 \\
7 & 7 & 3 & 150 \\
8 & 7 & 1 & 343 \\
9 & 4 & 9 & 168 \\
10 & 3 & 8 & 567 \\
11 & 9 & 10 & 960 \\
12 & 1 & 3 & 240 \\
13 & 2 & 4 & 790 \\
14 & 6 & 7 & 83 \\
15 & 6 & 8 & 570 \\
16 & 6 & 10 & 150 \\
17 & 4 & 2 & 1220 \\
18 & 10 & 8 & 110 \\
19 & 8 & 6 & 350 \\
20 & 9 & 6 & 410 \\
21 & 3 & 2 & 300 \\
22 & 5 & 2 & 130 \\
23 & 11 & 6 & 225 \\
24 & 5 & 7 & 850 \\
25 & 6 & 7 & 500 \\
26 & 2 & 1 & 275 \\
27 & 8 & 4 & 150 \\
28 & 10 & 11 & 800 \\
29 & 5 & 3 & 175 \\
30 & 10 & 9 & 87 \\
\hline & & &
\end{tabular}

Table 3 Parameters used in the case study

\begin{tabular}{ccccc}
\hline $\begin{array}{c}\text { Transportation } \\
\text { mode }\end{array}$ & $\begin{array}{c}\text { Capacity } \\
\text { (Tonne) }\end{array}$ & $\begin{array}{c}\text { Variable Cost } \\
\text { (£per ton-mile) }\end{array}$ & $\begin{array}{c}\text { Transfer Cost } \\
\text { (£per tonne) }\end{array}$ & $\begin{array}{c}\mathrm{CO}_{2} \\
\text { (g/tonne-km) }\end{array}$ \\
\hline Truck & 29 & 0.036 & 1.391 & 62 \\
Rail & 397 & 0.0425 & 1.391 & 22 \\
Ship & 2970 & 0.025 & 1.391 & 16 \\
\hline
\end{tabular}

brake et al, 2008b). As for the unit cost of emissions, we use the aforementioned value of $£ 71.6$ per tonne (The World Bank, 2012).

Since there are three modes used in our case study, there are three corresponding fixed cost. Estimates of fixed cost in the literature varied significantly. Instead we decide to look at a range of scenarios and investigate how these scenarios influence the solution. Fixed cost is one possible mean by which government policy can influence the transportation goods. We denote fixed cost by $f_{t}, f_{r}$ and $f_{s}$ for truck, rail and ship. The relationships between them can be written as: 


$$
\begin{aligned}
& f_{r}=\alpha f_{t}, \\
& f_{s}=\beta f_{t},
\end{aligned}
$$

where $\alpha$ and $\beta$ are positive integers.

To see the impact of fixed cost at the optimal structure and send the correct economic signals, we test a number of scenarios by changing the values of $\alpha, \beta$ and $f_{t}$ in our case study. When the value of $f_{t}$ is fixed, the value of $\alpha$ and $\beta$ are combinations of 1,3 and 5 . So for each $f_{t}$, there are nine different combinations. We assume the fixed cost for truck are $£ 50, £ 100$ and $£ 150$, respectively. The number of instances and corresponding fixed costs given different $f_{r}$ and $f_{s}$ are shown in Table 4 . In total there are 27 combinations.

Table 4 Fixed $\operatorname{costs}(£)$ for instances with different $\alpha$ and $\beta$

\begin{tabular}{c|c|c|c|c|c|c|c|c}
\hline \multirow{2}{*}{ Instance No. } & \multirow{2}{*}{$\alpha$} & \multirow{2}{*}{$\beta$} & \multicolumn{2}{|c|}{$f_{t}=50$} & \multicolumn{2}{c|}{$f_{t}=100$} & \multicolumn{2}{c}{$f_{t}=150$} \\
\cline { 4 - 8 } & & & $f_{r}$ & $f_{s}$ & $f_{r}$ & $f_{s}$ & $f_{r}$ & $f_{s}$ \\
\hline 1 & 1 & 1 & 50 & 50 & 100 & 100 & 150 & 150 \\
2 & 1 & 3 & 50 & 150 & 100 & 300 & 150 & 450 \\
3 & 1 & 5 & 50 & 250 & 100 & 500 & 150 & 750 \\
4 & 3 & 1 & 150 & 50 & 300 & 100 & 450 & 150 \\
5 & 3 & 3 & 150 & 150 & 300 & 300 & 450 & 450 \\
6 & 3 & 5 & 150 & 250 & 300 & 500 & 450 & 750 \\
7 & 5 & 1 & 250 & 50 & 500 & 100 & 750 & 150 \\
8 & 5 & 3 & 250 & 150 & 500 & 300 & 750 & 450 \\
9 & 5 & 5 & 250 & 250 & 500 & 500 & 750 & 750 \\
\hline
\end{tabular}

\subsection{Computational Results and Analysis}

Based on the data set introduced in Section 3.1, the computational testing for our model is performed using CPLEX Interactive Optimized 12.4.0.0 on a Lenovo ThinkPad T410 laptop computer with Intel Core i5 CPU and 4G RAM. For each instance, the resulting integer linear programming formulation has 8760 continuous and 292 integers. The computational time required to solve the integer model to optimality is 1.89 seconds for each instance.

\subsubsection{The Effect of Emission and Transfer Costs}

In this section, we provide results of nine experiments when $f_{t}=£ 50$ to show the effect of incorporating transfer and emission costs into the model. For this purpose, we first solve the model without the emission cost (4) and transfer cost (5), and denote this by $\mathrm{M}$. The total cost generated by $\mathrm{M}$ is the total operational transportation cost, including variable cost and fixed cost. Using the solutions obtained, we calculate the resulting emission cost $\mathrm{M}+\mathrm{G}$ and transfer cost $\mathrm{M}+\mathrm{T}$, as a consequence of solving $\mathrm{M}$. Then we solve the model 
with objective (4) denoted $\mathrm{M}(\mathrm{G})$, with objective (5) denoted $\mathrm{M}(\mathrm{T})$ and with both, denoted $M(G+T)$. Finally, the percentage savings obtained by $M(G)$, $\mathrm{M}(\mathrm{T})$ and $\mathrm{M}(\mathrm{G}+\mathrm{T})$ over the solutions provided by $\mathrm{M}+\mathrm{G}, \mathrm{M}+\mathrm{T}$ and $\mathrm{M}+\mathrm{G}+\mathrm{T}$ are calculated. The results of these experiments are represented in Tables $5-7$, along with the averages calculated across the nine instances.

Table 5 Computational results of models with and without emission cost

\begin{tabular}{ccccccc}
\hline & $\mathrm{M}+\mathrm{G}$ & & $\mathrm{M}(\mathrm{G})$ & \multicolumn{3}{c}{ Savings } \\
\hline & $\begin{array}{c}\text { Operational } \\
\text { Cost }(£)\end{array}$ & $\begin{array}{c}\text { Emission } \\
\text { Cost }(£)\end{array}$ & $\begin{array}{c}\text { Operational } \\
\text { Cost }(£)\end{array}$ & $\begin{array}{c}\text { Emission } \\
\text { Cost }(£)\end{array}$ & $\begin{array}{c}\text { Emission } \\
\text { Cost }(\%)\end{array}$ & $\begin{array}{c}\text { Total } \\
\text { Cost }(\%)\end{array}$ \\
\hline 1 & 77849 & 6545 & 78458 & 5015 & 23.38 & 1.09 \\
2 & 78949 & 6545 & 79558 & 4991 & 23.74 & 1.11 \\
3 & 79949 & 6545 & 80558 & 4991 & 23.74 & 1.09 \\
4 & 80098 & 6518 & 81053 & 5148 & 21.02 & 0.48 \\
5 & 81235 & 6744 & 82190 & 5158 & 23.52 & 0.72 \\
6 & 82235 & 6845 & 83190 & 5168 & 24.50 & 0.81 \\
7 & 82020 & 7167 & 82581 & 6016 & 16.06 & 0.66 \\
8 & 83134 & 7076 & 83696 & 6016 & 14.98 & 0.55 \\
9 & 84134 & 7076 & 84696 & 6016 & 14.98 & 0.55 \\
\hline Average & 81067 & 6785 & 81776 & 5391 & 20.66 & 0.78 \\
\hline
\end{tabular}

Table 6 Computational results of models with and without transfer cost

\begin{tabular}{ccccccc}
\hline & $\mathrm{M}+\mathrm{T}$ & $\mathrm{M}(\mathrm{T})$ & \multicolumn{3}{c}{ Savings } \\
\hline & $\begin{array}{c}\text { Operational } \\
\text { Cost }(£)\end{array}$ & $\begin{array}{c}\text { Transfer } \\
\text { Cost }(£)\end{array}$ & $\begin{array}{c}\text { Operational } \\
\text { Cost }(£)\end{array}$ & $\begin{array}{c}\text { Transfer } \\
\text { Cost }(£)\end{array}$ & $\begin{array}{c}\text { Transfer } \\
\text { Cost }(\%)\end{array}$ & $\begin{array}{c}\text { Total } \\
\text { Cost }(\%)\end{array}$ \\
\hline 1 & 77849 & 3392 & 78266 & 2708 & 20.17 & 0.33 \\
2 & 78949 & 3396 & 79466 & 2498 & 26.44 & 0.46 \\
3 & 79949 & 3392 & 81516 & 1308 & 61.44 & 0.62 \\
4 & 80098 & 3263 & 81316 & 1774 & 45.63 & 0.33 \\
5 & 81235 & 3431 & 82755 & 1315 & 61.67 & 0.70 \\
6 & 82235 & 3264 & 83655 & 1315 & 59.71 & 0.62 \\
7 & 82020 & 3278 & 83478 & 1315 & 59.88 & 0.59 \\
8 & 83134 & 3435 & 84415 & 1315 & 61.72 & 0.97 \\
9 & 84134 & 3452 & 85315 & 1315 & 20.17 & 0.33 \\
\hline Average & 81067 & 3367 & 82242 & 1651 & 51.97 & 0.64 \\
\hline
\end{tabular}

As shown in Table 5, M generated at least £6545 emission cost for each instance. Considering GHG emissions in the objective function significantly decreases the emission cost, with an average saving of $20.66 \%$. Since operational cost accounts for most of the total cost, the savings are between $0.48 \%$ and $1.11 \%$, which is around $£ 4300-£ 8000$. In Table 6 , it can be seen that M generated around $£ 3400$ transfer cost for each instance. In contrast, M(T) yields an average savings of $51.97 \%$. The significance of the results shown in both tables is that that solutions of similar cost to $\mathrm{M}+\mathrm{G}$ and $\mathrm{M}+\mathrm{T}$ can be 
Table 7 Computational results of models with and without emission and transfer costs

\begin{tabular}{|c|c|c|c|c|c|c|c|c|c|}
\hline & & $\mathrm{M}+\mathrm{G}+\mathrm{T}$ & & & $\mathrm{M}(\mathrm{G}+\mathrm{T})$ & & & Savings & \\
\hline & $\begin{array}{c}\text { Operational } \\
\text { Cost }(£)\end{array}$ & $\begin{array}{l}\text { Emission } \\
\text { Cost }(£) \\
\end{array}$ & $\begin{array}{l}\text { Transfer } \\
\text { Cost }(£) \\
\end{array}$ & $\begin{array}{c}\text { Operational } \\
\text { Cost }(£)\end{array}$ & $\begin{array}{l}\text { Emission } \\
\text { Cost }(£) \\
\end{array}$ & $\begin{array}{l}\text { Transfer } \\
\text { Cost }(£) \\
\end{array}$ & $\begin{array}{l}\text { Emission } \\
\text { Cost }(\%) \\
\end{array}$ & $\begin{array}{l}\text { Transfer } \\
\text { Cost }(\%) \\
\end{array}$ & $\begin{array}{c}\text { Total } \\
\text { Cost }(\%)\end{array}$ \\
\hline 1 & 77849 & 6545 & 3392 & 78527 & 5920 & 2806 & 9.55 & 17.28 & 0.61 \\
\hline 2 & 78949 & 6545 & 3396 & 79727 & 5900 & 2596 & 9.85 & 23.56 & 0.75 \\
\hline 3 & 79949 & 6545 & 3392 & 80627 & 5900 & 2596 & 9.85 & 23.47 & 0.85 \\
\hline 4 & 80098 & 6518 & 3263 & 80930 & 6066 & 2708 & 6.93 & 17.01 & 0.19 \\
\hline 5 & 81235 & 6744 & 3431 & 82217 & 6075 & 2498 & 9.92 & 27.19 & 0.68 \\
\hline 6 & 82235 & 6845 & 3264 & 83217 & 6075 & 1498 & 11.25 & 54.11 & 1.68 \\
\hline 7 & 82020 & 7167 & 3278 & 82925 & 6336 & 2708 & 11.59 & 17.39 & 0.54 \\
\hline 8 & 83134 & 7076 & 3435 & 84039 & 6336 & 2708 & 10.46 & 21.16 & 0.60 \\
\hline 9 & 84134 & 7076 & 3452 & 85039 & 6336 & 2708 & 10.46 & 21.55 & 0.61 \\
\hline Average & 81067 & 6785 & 3367 & 81916 & 6105 & 2536 & 9.98 & 24.75 & 0.72 \\
\hline
\end{tabular}

obtained with our models, but those that are with significantly less emission and transfer costs. Table 7 shows the comparison of results between $\mathrm{M}+\mathrm{G}+\mathrm{T}$ and $\mathrm{M}(\mathrm{G}+\mathrm{T})$. In this case, emission cost in $\mathrm{M}(\mathrm{G}+\mathrm{T})$ is reduced by between $6.93 \%$ and $11.59 \%$ compared to that generated by M. Similarly, intermodal transfer cost is also reduced by up to $54.11 \%$. The average savings in the total cost obtained by using $\mathrm{M}(\mathrm{G}+\mathrm{T})$ is $0.72 \%$ on average. However, it is noteworthy that these solutions again exhibit an average savings of $9.98 \%$ on emission cost and $24.75 \%$ on transfer cost.

\subsubsection{Intermodal vs. Unimodal Transportation}

In our next set of experiments, we seek to compare unimodal with intermodal transportation. Since Birmingham and Manchester are inland, transportation by ship is not available for these nodes. As a result we only test truck only and rail only models for uni-modal transportation. We test scenarios for unimodal and intermodal transportation models with $f_{t}=f_{r}=f_{s}=£ 50, f_{t}=f_{r}=f_{s}=£ 100$ and $f_{t}=f_{r}=f_{s}=£ 150$, to delete the effects of different fixed cost when comparing the result. Computational results are summarized in Table 8. The third column displays the total cost for shipping commodities. The fourth, fifth, sixth and seventh columns display the variable costs, fixed costs, emission cost and intermodal transfer cost, respectively.

When the fixed cost is $£ 50$, the total costs for truck only, rail only and intermodal transportation are $£ 112513$, £98778 and $£ 87253$. Intermodal transportation is $22.4 \%$ and $11.7 \%$ less costly than truck only and rail only transportation. When the fixed costs increase to $£ 100$ and $£ 150$, the total savings that intermodal transportation affords is up to $41.2 \%$.

Variable cost of the three truck only scenarios changes from $£ 75730$ to $£ 75775$, which is a $0.06 \%$ change. For rail only scenarios, variable cost stays the same. Unlike uni-modal results, variable cost of intermodal scenarios changes from $£ 75327$ to $£ 77705$, which is $3.1 \%$ increase when fixed cost increases from $£ 50$ to $£ 100$. A larger range of change indicates that when fixed cost is less 
Table 8 Comparison of the results of the uni-modal and intermodal transportation

\begin{tabular}{c|c|c|c|c|c|c}
\hline & $\begin{array}{c}\text { Modal } \\
\text { Type }\end{array}$ & $\begin{array}{c}\text { Total } \\
\text { Cost }(£)\end{array}$ & $\begin{array}{c}\text { Variable } \\
\text { Cost }(£)\end{array}$ & $\begin{array}{c}\text { Fixed } \\
\text { Cost }(£)\end{array}$ & $\begin{array}{c}\text { Emission } \\
\text { Cost }(£)\end{array}$ & $\begin{array}{c}\text { Transfer } \\
\text { Cost }(£)\end{array}$ \\
\hline \multirow{3}{*}{$f_{t}=f_{r}=f_{s}=£ 50$} & Truck only & 112513 & 75730 & 21550 & 15233 & 0 \\
& Rail only & 98778 & 91326 & 2100 & 5352 & 0 \\
& Intermodal & 87253 & 75327 & 3200 & 5920 & 2806 \\
\hline \multirow{3}{*}{$f_{t}=f_{r}=f_{s}=£ 100$} & Truck only & 134019 & 75775 & 43000 & 15244 & 0 \\
& Rail only & 100878 & 91326 & 4200 & 5352 & 0 \\
& Intermodal & 89465 & 77705 & 3900 & 5020 & 2840 \\
\hline \multirow{2}{*}{$f_{t}=f_{r}=f_{s}=£ 150$} & Truck only & 155519 & 75775 & 64500 & 15244 & 0 \\
& Rail only & 102978 & 91326 & 6300 & 5352 & 0 \\
& Intermodal & 91415 & 77705 & 5850 & 5020 & 2840 \\
\hline
\end{tabular}

than $£ 100$, it has a greater effect on variable cost in intermodal transportation than that in uni-modal transportation. When fixed cost increases from $£ 100$ to $£ 150$, variable cost of uni-modal and intermodal models do not change. It is possible that variable cost reaches its maximal value and will not be affected by the change of fixed cost.

Since the emission factor of truck is the highest, followed by ship and rail, the emission cost for truck only transportation is nearly three times costly than that of rail only and intermodal transportation. We notice that there is only a slight change for emission cost in truck only transportation by adjusting fixed cost, while for rail only transportation, emission cost stays the same. In intermodal transportation, emission cost decreases from $£ 5920$ to $£ 5020$, a $15.2 \%$ decrease. When fixed cost keeps increasing, emission cost does not change. Reducing emission cost can be obtained by adjusting fixed cost when fixed cost is less than $£ 100$.

Transfer cost is only occurred in intermodal transportation. It is the smallest part of the total cost. When fixed cost increases from $£ 50$ to $£ 150$, the transfer cost increases slightly from $£ 2806$ to $£ 2840$. More details on this are provided in the next section where intermodal transportation results are discussed.

In sum, even if transfer cost is incurred in intermodal transportation, the total costs can be reduced by $11.3 \%-41.2 \%$ by using intermodal transportation as opposed to uni-modal transportation. By adjusting fixed cost, variable cost and emission cost can be reduced in intermodal transportation, while they rarely change in uni-modal transportation. These results indicate that intermodal transportation is more flexible than uni-modal transportation.

\subsubsection{Intermodal Transportation Results}

The results presented in Figure 5-7 show the total cost, including variable cost, fixed cost, emission cost and intermodal transfer cost, for 9 intermodal instances when $f_{t}=£ 50, £ 100$ and $£ 150$, respectively. From these figures, we notice that variable cost, which is around $£ 75000$, takes up the largest proportion of the total cost and it does not change greatly across the 27 instances. Intermodal transfer cost takes up the least proportion. For each $f_{t}$, the total 


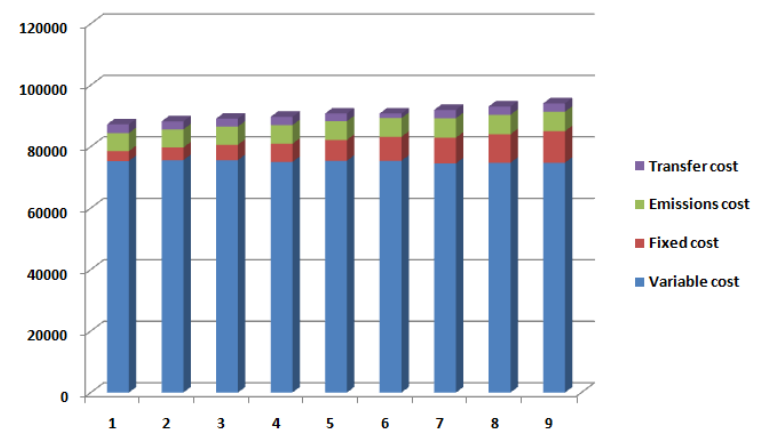

Fig. 5 Computational results for 9 intermodal instances when $f_{t}=50$

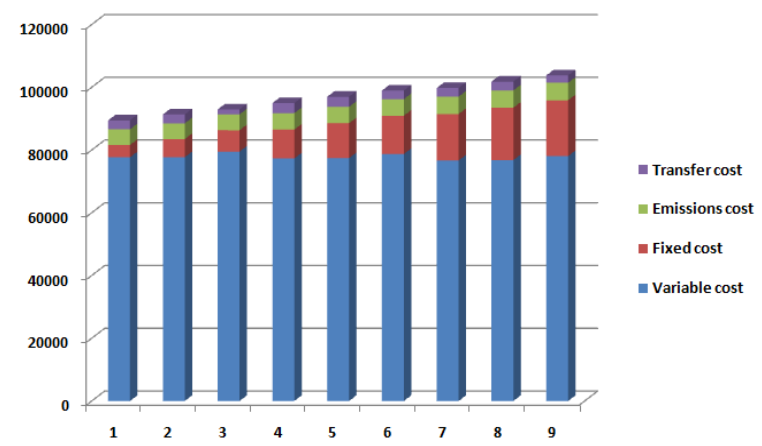

Fig. 6 Computational results for 9 intermodal instances when $f_{t}=100$

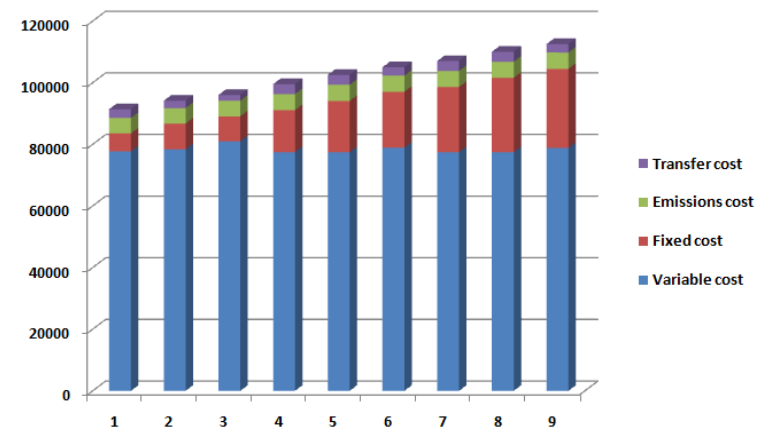

Fig. 7 Computational results for 9 intermodal instances when $f_{t}=150$

fixed cost increases when $f_{r}$ or $f_{s}$ is increasing. Hence, the total cost is also increasing. More details about the total cost and its components are presented in Table 9 , which shows costs that are normalized to 1 against base case scenarios of $f_{t}=f_{r}=f_{s}$, for all 27 instances.

Table 9 shows that when $f_{t}=£ 50$, total cost for 9 instances is normalized to a range of 1.000-1.078. For each $f_{t}$, the total fixed cost is increasing when $f_{r}$ 
Table 9 Normalized costs for intermodal instances

\begin{tabular}{|c|c|c|c|c|c|c|c|}
\hline$f_{t}$ & $f_{r}$ & $f_{s}$ & $\begin{array}{l}\text { Total } \\
\text { Cost }\end{array}$ & $\begin{array}{c}\text { Variable } \\
\text { Cost }\end{array}$ & $\begin{array}{c}\text { Fixed } \\
\text { Cost }\end{array}$ & $\begin{array}{c}\text { Emission } \\
\text { Cost }\end{array}$ & $\begin{array}{c}\text { Transfer } \\
\text { Cost }\end{array}$ \\
\hline \multirow{9}{*}{$£ 50$} & \multirow{3}{*}{$£ 50$} & $£ 50$ & 1.000 & 1.000 & 1.000 & 1.000 & 1.000 \\
\hline & & $£ 150$ & 1.011 & 1.004 & 1.281 & 0.997 & 0.925 \\
\hline & & $£ 250$ & 1.021 & 1.004 & 1.563 & 0.997 & 0.925 \\
\hline & \multirow{3}{*}{$£ 150$} & $£ 50$ & 1.028 & 0.996 & 1.844 & 1.025 & 0.965 \\
\hline & & $£ 150$ & 1.041 & 1.001 & 2.125 & 1.026 & 0.890 \\
\hline & & $£ 250$ & 1.041 & 1.001 & 2.438 & 1.026 & 0.534 \\
\hline & \multirow{3}{*}{$£ 250$} & $£ 50$ & 1.054 & 0.990 & 2.609 & 1.070 & 0.965 \\
\hline & & $£ 150$ & 1.067 & 0.993 & 2.891 & 1.070 & 0.965 \\
\hline & & $£ 250$ & 1.078 & 0.993 & 3.203 & 1.070 & 0.965 \\
\hline \multirow{9}{*}{$£ 100$} & \multirow{3}{*}{$£ 100$} & $£ 100$ & 1.000 & 1.000 & 1.000 & 1.000 & 1.000 \\
\hline & & $£ 300$ & 1.021 & 1.000 & 1.487 & 0.996 & 1.000 \\
\hline & & $£ 500$ & 1.039 & 1.023 & 1.744 & 1.003 & 0.559 \\
\hline & \multirow{3}{*}{$£ 300$} & $£ 100$ & 1.062 & 0.995 & 2.359 & 1.044 & 1.129 \\
\hline & & $£ 300$ & 1.084 & 0.997 & 2.846 & 1.042 & 1.129 \\
\hline & & $£ 500$ & 1.106 & 1.013 & 3.128 & 1.057 & 0.963 \\
\hline & \multirow{3}{*}{$£ 500$} & $£ 100$ & 1.115 & 0.987 & 3.795 & 1.103 & 0.982 \\
\hline & & $£ 300$ & 1.138 & 0.988 & 4.282 & 1.101 & 0.982 \\
\hline & & $£ 500$ & 1.160 & 1.005 & 4.564 & 1.116 & 0.816 \\
\hline \multirow{9}{*}{$£ 150$} & \multirow{3}{*}{$£ 150$} & $£ 150$ & 1.000 & 1.000 & 1.000 & 1.000 & 1.000 \\
\hline & & $£ 450$ & 1.030 & 1.009 & 1.436 & 0.998 & 0.840 \\
\hline & & $£ 750$ & 1.050 & 1.042 & 1.385 & 1.017 & 0.649 \\
\hline & \multirow{3}{*}{$£ 450$} & $£ 150$ & 1.089 & 0.997 & 2.333 & 1.042 & 1.129 \\
\hline & & $£ 450$ & 1.122 & 0.997 & 2.846 & 1.042 & 1.129 \\
\hline & & $£ 750$ & 1.149 & 1.016 & 3.103 & 1.042 & 0.963 \\
\hline & \multirow{3}{*}{$£ 750$} & $£ 150$ & 1.171 & 0.997 & 3.615 & 1.042 & 1.129 \\
\hline & & $£ 450$ & 1.204 & 0.997 & 4.128 & 1.042 & 1.129 \\
\hline & & $£ 750$ & 1.231 & 1.015 & 4.385 & 1.057 & 0.969 \\
\hline
\end{tabular}

or $f_{s}$ is increasing. It is interesting that the variable cost almost stays the same when fixed cost changes. The difference is between $0.1 \%$ and $2.3 \%$. For most of the instances, the emission cost slightly increases when $f_{r}$ or $f_{s}$ is increasing. The emission cost increases up to $11.6 \%$. We have mentioned in Section 3.1 that emission cost is measured by the product of distance, amount of load and emissions factor. We also know that emissions factor for truck is the highest, followed by ship and rail. So when $f_{r}$ or $f_{s}$ is increasing, total truck tonnemiles increase, which leads the result that total emission cost increases. Since rail and ship have lower emissions factors than truck, reducing $f_{r}$ and $f_{s}$ helps reducing emission cost in intermodal transportation. Transfer cost also does not change significantly. From Table 8 , we already know that the transfer cost is aroung $£ 2800$ when $f_{t}=f_{r}=f_{s}$. Except two instances out of 27 , the change of transfer cost is between $18.4 \%$ and $3.1 \%$, which means intermodal transfer is a very important component in intermodal tansportation chain. Consolidation of loads or incentivizing certain low emissions forms of transportation can be efficiently achieved in intermodal transportation.

Table 10-12 list the total tonnage shipped and the capacity utilization of three transport modes when $f_{t}=£ 50, £ 100$ and $£ 150$ with the commodities shown in Table 2. From instance 1 to 9 in each table, either $f_{r}$ or $f_{s}$ is increasing, as shown in Table 4 . We notice that more trucks are used and greater total 
Table 10 Comparison of the capacity utilization for 3 modes when $f_{t}=£ 50$

\begin{tabular}{cccccccccc}
\hline & \multicolumn{3}{c}{ Truck } & \multicolumn{3}{c}{ Rail } & \multicolumn{2}{c}{ Ship } \\
\hline & $\begin{array}{c}\text { Total } \\
\text { No. }\end{array}$ & $\begin{array}{c}\text { Total } \\
\text { tonnage }\end{array}$ & $\begin{array}{c}\text { Capacity } \\
\text { utilization(\%) }\end{array}$ & $\begin{array}{c}\text { Total } \\
\text { No. }\end{array}$ & $\begin{array}{c}\text { Total } \\
\text { tonnage }\end{array}$ & $\begin{array}{c}\text { Capacity } \\
\text { utilization(\%) }\end{array}$ & $\begin{array}{c}\text { Total } \\
\text { No. }\end{array}$ & $\begin{array}{c}\text { Total } \\
\text { tonnage }\end{array}$ & $\begin{array}{c}\text { Capacity } \\
\text { utilization(\%) }\end{array}$ \\
\hline 1 & 26 & 741 & 98.28 & 27 & 8265 & 77.11 & 11 & 6306 & 19.30 \\
2 & 26 & 741 & 98.28 & 29 & 9375 & 81.43 & 9 & 5196 & 19.44 \\
3 & 26 & 741 & 98.28 & 29 & 9375 & 81.43 & 9 & 5196 & 19.44 \\
4 & 34 & 939 & 95.23 & 24 & 7666 & 80.46 & 12 & 6323 & 17.74 \\
5 & 34 & 939 & 95.23 & 24 & 8063 & 84.62 & 10 & 6013 & 20.25 \\
6 & 34 & 939 & 95.23 & 24 & 8063 & 84.62 & 10 & 6013 & 20.25 \\
7 & 45 & 1253 & 96.02 & 22 & 7352 & 84.18 & 12 & 6496 & 18.23 \\
8 & 45 & 1253 & 96.02 & 22 & 7352 & 84.18 & 10 & 6410 & 21.58 \\
9 & 45 & 1253 & 96.02 & 22 & 7352 & 84.18 & 10 & 6410 & 21.58 \\
\hline
\end{tabular}

Table 11 Comparison of the capacity utilization for 3 modes when $f_{t}=£ 100$

\begin{tabular}{|c|c|c|c|c|c|c|c|c|c|}
\hline \multicolumn{4}{|c|}{ Truck } & \multicolumn{3}{|c|}{ Rail } & \multicolumn{3}{|c|}{ Ship } \\
\hline & $\begin{array}{l}\text { Total } \\
\text { No. }\end{array}$ & $\begin{array}{l}\text { Total } \\
\text { tonnage }\end{array}$ & $\begin{array}{c}\text { Capacity } \\
\text { utilization }(\%)\end{array}$ & $\begin{array}{l}\text { Total } \\
\text { No. }\end{array}$ & $\begin{array}{c}\text { Total } \\
\text { tonnage }\end{array}$ & $\begin{array}{c}\text { Capacity } \\
\text { utilization }(\%)\end{array}$ & $\begin{array}{l}\text { Total } \\
\text { No. }\end{array}$ & $\begin{array}{c}\text { Total } \\
\text { tonnage }\end{array}$ & $\begin{array}{c}\text { Capacity } \\
\text { utilization }(\%)\end{array}$ \\
\hline 1 & 0 & 0 & $\mathrm{~N} / \mathrm{A}$ & 29 & 9035 & 78.48 & 10 & 6257 & 21.07 \\
\hline 2 & 0 & 0 & $\mathrm{~N} / \mathrm{A}$ & 31 & 9748 & 79.21 & 9 & 5544 & 20.74 \\
\hline 3 & 0 & 0 & $\mathrm{~N} / \mathrm{A}$ & 33 & 10095 & 77.06 & 7 & 4463 & 21.47 \\
\hline 4 & 6 & 174 & 100.00 & 25 & 8613 & 86.78 & 11 & 6939 & 21.24 \\
\hline 5 & 6 & 174 & 100.00 & 25 & 8613 & 86.78 & 10 & 6766 & 22.78 \\
\hline 6 & 7 & 186 & 91.63 & 25 & 8589 & 86.54 & 8 & 6647 & 27.98 \\
\hline 7 & 17 & 476 & 96.55 & 24 & 8141 & 85.44 & 11 & 6641 & 20.33 \\
\hline 8 & 17 & 476 & 96.55 & 24 & 8141 & 85.44 & 10 & 6468 & 21.78 \\
\hline 9 & 18 & 488 & 93.49 & 24 & 8117 & 85.19 & 8 & 6349 & 26.72 \\
\hline
\end{tabular}

Table 12 Comparison of the capacity utilization for 3 modes when $f_{t}=£ 150$

\begin{tabular}{cccccccccc}
\hline & \multicolumn{3}{c}{ Truck } & \multicolumn{2}{c}{ Rail } & \multicolumn{2}{c}{ Ship } \\
\hline $\begin{array}{c}\text { Total } \\
\text { No. }\end{array}$ & $\begin{array}{c}\text { Total } \\
\text { tonnage }\end{array}$ & $\begin{array}{c}\text { Capacity } \\
\text { utilization(\%) }\end{array}$ & $\begin{array}{c}\text { Total } \\
\text { No. }\end{array}$ & $\begin{array}{c}\text { Total } \\
\text { tonnage }\end{array}$ & $\begin{array}{c}\text { Capacity } \\
\text { utilization(\%) }\end{array}$ & $\begin{array}{c}\text { Total } \\
\text { No. }\end{array}$ & $\begin{array}{c}\text { Total } \\
\text { tonnage }\end{array}$ & $\begin{array}{c}\text { Capacity } \\
\text { utilization(\%) }\end{array}$ \\
\hline 1 & 0 & 0 & N/A & 29 & 9035 & 78.48 & 10 & 6257 & 21.07 \\
2 & 0 & 0 & N/A & 32 & 9848 & 77.52 & 8 & 5033 & 21.18 \\
3 & 0 & 0 & N/A & 34 & 10772 & 79.80 & 4 & 4078 & 34.33 \\
4 & 6 & 174 & 100.00 & 25 & 8613 & 86.78 & 10 & 6766 & 22.78 \\
5 & 6 & 174 & 100.00 & 25 & 8613 & 86.78 & 10 & 6766 & 22.78 \\
6 & 3 & 87 & 100.00 & 26 & 8688 & 84.17 & 8 & 6647 & 27.98 \\
7 & 6 & 174 & 100.00 & 25 & 8613 & 86.78 & 10 & 6766 & 22.78 \\
8 & 6 & 174 & 100.00 & 25 & 8613 & 86.78 & 10 & 6766 & 22.78 \\
9 & 6 & 174 & 100.00 & 25 & 8613 & 86.78 & 8 & 6671 & 28.08 \\
\hline
\end{tabular}


tonnage of commodities are transported by truck when $f_{r}$ or $f_{s}$ is increasing. Except for six instances in total, in which no trucks are used for shipping, the capacity utilization for other instances stays above $91 \%$. In eight out of these 22 instances, the capacity utilization reaches $100 \%$ for truck. By adjusting $f_{t}$, we could avoid the situation that there are no trucks used in the transportation network and at the same time, get a relatively high capacity utilization. For rail, when $f_{r}$ increases, both total tonnage and total number of vehicles used decreases, while the capacity utilization increases. One reason might be that it is more cost effective to travel further to consolidate onto fewer vehicles when $f_{r}$ is high. When $f_{r}$ is low, using more vehicles on direct routes could be more attractive. The capacity utilization of rail across the 27 instances is greater than $77 \%$ for all. In 17 out of 27 instances, it is greater than $84 \%$. When $f_{t}$ increases, the total tonnage transported by rail is increasing. By changing $f_{t}$ or $f_{r}$, we might roughly control the total tonnage for rail. Since ships have large capacity, the average capacity utilization of ship is much less than that of truck and rail, with values around $20 \%$. Due to its large capacity, the number of ships used and total tonnage of commodities transported also do not change as much as that of trucks and ships.

As part of the computational experiments, we have conducted further tests where costs of rail are changed and demands are increased. In the case that the variable cost and capacity of rail are changed to $£ 0.017$ per ton-mile and 3360 tonnes (Forkenbrock, 2001), the results with the intermodal model suggested a uni-modal transportation plan with rail being the only mode of transport used and ship very rarely. The capacity utilization for rail is $18 \%$ to $32 \%$. In the event that demands are increased 10 -fold, the results do not significantly change although the capacity utilization of rail and ship has increased. Rail has a much higher capacity utilization of more than $96 \%$ and ship being more used with capacity utilization of between $76 \%$ and $88 \%$. Computational results for this case can be found in Table 13-15 in the Appendix.

\section{Bi-criteria analysis}

In this paper, the multimode multicommodity network design problem has so far been treated as a single-objective optimization problem. This was made possible by aggregating the two objective functions, one relevant to operational activities, and the other emissions, by attaching suitable cost coefficients to each. In this section, we show how the model can be used to produce non-dominated solutions with regard to the two objectives, if they are incommensurable. This analysis is particularly relevant if costs are not a prevailing factor, or are not readily available, as might be for emission costs. In multiobjective optimization, a non-dominated, or Pareto-optimal, solution is where no objective can be improved without worsening at lease one other objective (Coello et al, 2007). The set of Pareto-optimal solutions form the Paretofrontier. Decision-makers usually select a particular Pareto-optimal solution based on their preferences on the objectives (Ghoseiri et al, 2004). 
In order to find the trade-offs between minimizing total transportation cost and the amount of $\mathrm{CO}_{2}$ emissions in the multicommodity multimodal service network design problem, we use the notation shown in Table 1 and define the two objective functions below:

$$
\begin{aligned}
(O B J 1) \quad f_{1}(x, y, z) & =\sum_{k \in K} \sum_{(i, j) \in A} \sum_{m \in M} c_{i j}^{m} x_{i j}^{k m} \\
& +\sum_{(i, j) \in A} \sum_{m \in M} f_{i j}^{m} y_{i j}^{m} \\
& +\frac{1}{2} w \sum_{i \in N} \sum_{k \in K}\left(\sum_{m \in M} z_{i}^{k m}-h_{i}^{k}\right) \\
(\text { OBJ } 2) \quad f_{2}(x) & =\sum_{k \in K} \sum_{(i, j) \in A} \sum_{m \in M} d_{i j}^{m} e^{m} x_{i j}^{k m} .
\end{aligned}
$$

In the above, $f_{1}(x, y, z)$ measures the total transportation cost, including variable cost, fixed cost and transfer cost, which are detailed in Section 3.2. On the other hand, $f_{2}(x)$ measures the total $\mathrm{CO}_{2}$ emission for all activities. Let $S$ denote the feasible set defined by the equality and inequality constraints (6)-(9), (12) and (13) as described in Section 3.3.

A number of methods have been suggested to generate the Pareto frontier in multi-objective programming, such as goal programming, bound objective function formulations and genetic algorithms. In this paper, we use the $\epsilon$ constraint method, which is easy to implement and effective. In this method, one of the objectives is optimized, subject to other objective converted into a constraint by imposing appropriate upper bounds on its value. The $\epsilon$-constraint method can be implemented as follows (Mavrotas, 2009; Engau and Wiecek, 2007). We first solve the following single-objective optimization problem:

$$
\begin{array}{cl}
\text { Minimize } & f_{2}(x) \\
\text { subject to } & x \in S .
\end{array}
$$

Let an optimal solution vector of $(24)-(25)$ be denoted by $\left(x_{2}^{*}, y_{2}^{*}, z_{2}^{*}\right)$. The minimized amount of $\mathrm{CO}_{2}$ emissions is then fixed as $f_{2}\left(x_{2}^{*}\right)=\epsilon$. Following this step, we solve following next single-objective optimization model:

$$
\begin{aligned}
\text { Minimize } & f_{1}(x, y, z) \\
\text { subject to } & f_{2}(x) \leq \epsilon \\
& x, y, z \in S .
\end{aligned}
$$

Let $\left(x_{1}^{*}, y_{1}^{*}, z_{1}^{*}\right)$ denote an optimal solution to (26)-(28). Furthermore, let $q$ be the number of Pareto-optimal solutions that a decision-maker wishes to produce. Then, the value of $\epsilon$ is to be increased by $\varsigma$ at every iteration where:

$$
\varsigma=\left(f_{2}\left(x_{1}^{*}\right)-f_{2}\left(x_{2}^{*}\right)\right) /(q-1) .
$$

The method iterates by increasing the value of $\epsilon$ in this way (see Table 13), where each iteration generates another optimal solution. By repeatedly 
relaxing the upper bound on $f_{2}$, and resolving $f_{1}$ each time, solutions can be obtain to construct the Pareto-frontier.

Table 13 Value of $\epsilon$ in $\epsilon$-constraint approach

\begin{tabular}{cc}
\hline Iteration No. & Value of $\epsilon$ \\
\hline 1 & $f_{2}^{*}$ \\
2 & $f_{2}^{*}+\varsigma$ \\
3 & $f_{2}^{*}+2 \varsigma$ \\
$\cdots$ & $\ldots$ \\
$q-1$ & $f_{2}^{*}+(q-2) \varsigma$ \\
$q$ & $f_{2}\left(x_{1}^{*}\right)$ \\
\hline
\end{tabular}

We now present a numerical example to illustrate the application of the $\epsilon$-constraint method on the multimode multicommodity network design problem. The method is implemented in $\mathrm{C}$ and each sub-problem is solved to optimality by ILOG CPLEX Interactive Optimized 12.4. Therefore, the solutions generated are Pareto-optimal. The instances is based on the data presented in Section 4.1 with the fixed-cost scenario where $f_{t}=£ 50, f_{r}=£ 150$ and $f_{s}=£ 250$.

Assuming $q=45$, the stepsize is calculated as $\varsigma=0.7$ tonne. The resulting set of Pareto-optimal solutions are shown in Figure 8.

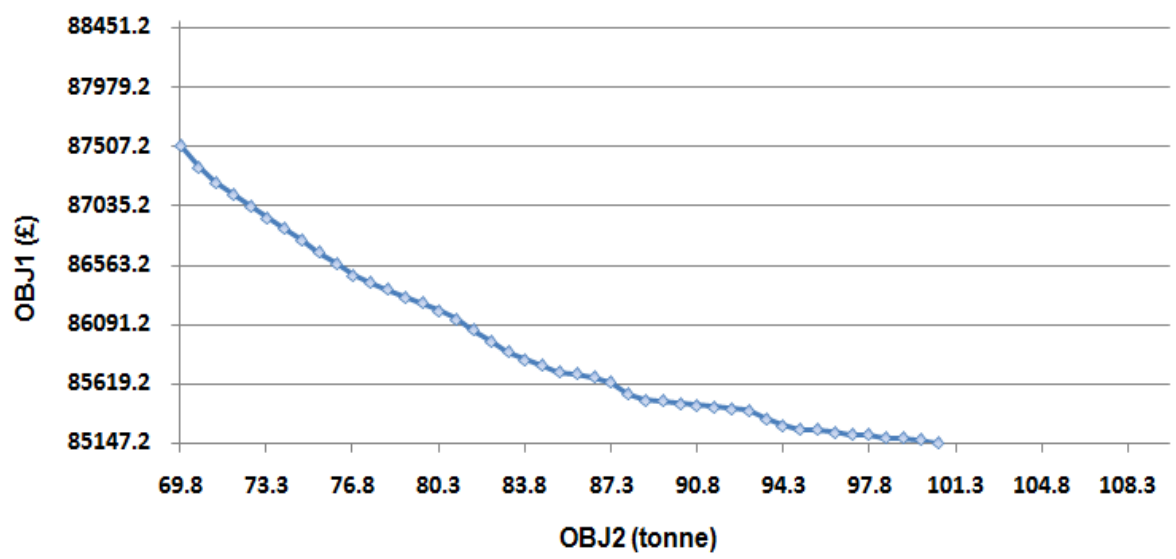

Fig. 8 Pareto optimal curve of MOO model

To select the most preferred solution from this set of non-dominated solutions, we have also implemented a normalized distance method, for which the two objectives are normalized as follows:

$$
\begin{gathered}
f_{1}(x, y, z)=\frac{f_{1}(x, y, z)-f_{1}\left(x_{1}^{*}, y_{1}^{*}, z_{1}^{*}\right)}{f_{1}\left(x_{2}^{*}, y_{2}^{*}, z_{2}^{*}\right)-f_{1}\left(x_{1}^{*}, y_{1}^{*}, z_{1}^{*}\right)} \in[0,1], \\
f_{2} \overline{(}(x)=\frac{f_{2}(x)-f_{2}\left(x_{2}^{*}\right)}{f_{2}\left(x_{1}^{*}\right)-f_{2}\left(x_{2}^{*}\right)} \in[0,1],
\end{gathered}
$$


where $\bar{f}_{1}$ and $\bar{f}_{2}$ are the normalized value of OBJ1 and OBJ2, respectively. Assuming an ideal point $(0,0)$, as shown in Figure 9, the solution that is closest can be considered as the most preferred solution.

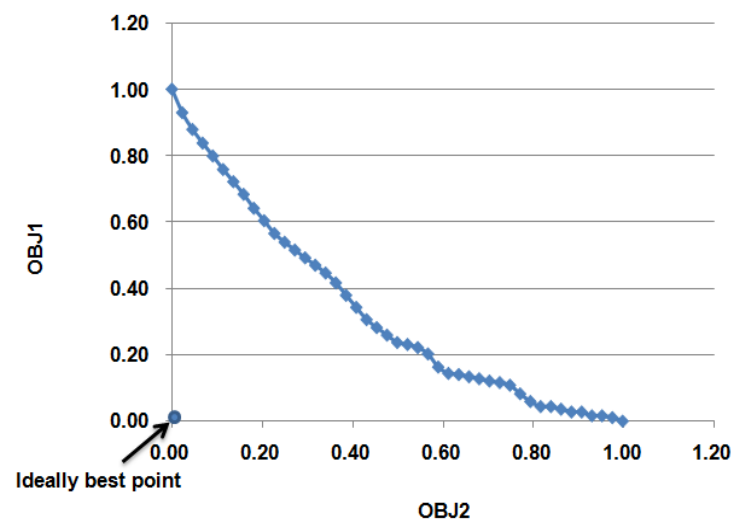

Fig. 9 Normalized Pareto optimal curve of MOO model

As seen in Figure 9, the normalized solution that yields the minimum distance from the ideal point is $\bar{f}_{1}=0.31$ and $\bar{f}_{2}=0.43$. Mapping this on the original functions, the values of the corresponding solutions are OBJ1=£85869.2 and OBJ2=83.1 tonne.

\section{Conclusions}

In this paper, we have described an intermodal freight transportation model, which also extends current service network design models by taking GHG emission cost into account. The model also includes a nonlinear expression for transfer cost at intermodal nodes, which can be linearized. We have also shown how the problem can be formulated as a bi-objective optimization model. The computational results have suggested that the proposed model provides costefficient and emission-efficient ways for transporting commodities. This makes it interesting for practical applications.

One important detail to remember is that the adjusted fixed costs are used for the purpose of sending the correct economic signals. We believe that it provides an opportunity for considerable cost reduction while adjusting fixed costs. By changing the value of fixed cost for three modes of transport, performance indicates emission cost, variable cost, capacity utilization for truck, rail and ship, and the tradeoffs between operational, emission and transfer costs can be analyzed. 


\section{Acknowledgements}

Thanks are due to three reviewers for their valuable comments and suggestions on the initial version of this paper. This study has been partially supported by funds provided by the University of Southampton which is gratefully acknowledged.

\section{References}

Andersson E, Berg M, Nelldal B, Fröidh O (2011) TOSCA: Rail freight transport : Techno-economic analysis of energy and greenhouse gas reductions. Tech. rep., KTH, Rail Vehicles, KTH, The KTH Railway Group, KTH, Traffic and Logistics

Arnold P, Peeters D, Thomas I (2004) Modelling a rail/road intermodal transportation system. Transportation Research Part E: Logistics and Transportation Review 40(3):255-270

Balakrishnan A, Magnanti TL, Wong RT (1989) A dual-ascent procedure for large-scale uncapacitated network design. Operations Research 37(5):716740

Bauer J, Bektaş T, Crainic TG (2009) Minimizing greenhouse gas emissions in intermodal freight transport: an application to rail service design. Journal of the Operational Research Society 61(3):530-542

Bektaş T, Crainic TG (2007) A brief overview of intermodal transportation. In: Taylor GD (ed) Logistics Engineering Handbook, CRC Press, Boca Raton

Ben-Ayed O, Blair CE, Boyce DE, LeBlanc LJ (1992) Construction of a realworld bilevel linear programming model of the highway network design problem. Annals of Operations Research 34(1):219-254

Campbell JF, Ernst AT, Krishnamoorthy M (2002) Hub arc location problems: Part I-Introduction and Results. Management Science 51(10):1540-1555

Christiansen M, Fagerholt K, Nygreen B, Ronen D (2007) Maritime transportation. In: Barnhart C, Laporte G (eds) Transportation, Handbooks in Operations Research and Management Science, vol 14, Elsevier, pp 189-284

Coello CAC, Lamont GB, Van Veldhuisen DA (2007) Evolutionary algorithms for solving multi-objective problems. Springer, Boston, MA

Crainic TG (2000) Service network design in freight transportation. European Journal of Operational Research 122(2):272-288

Crainic TG, Kim K (2007) Intermodal transportation. In: Barnhart C, Laporte G (eds) Transportation, Handbooks in Operations Research and Management Science, vol 14, Elsevier, pp 467-537

Crainic TG, Laporte G (1997) Planning models for freight transportation. European Journal of Operational Research 97(3):409-438

Crainic TG, Rousseau JM (1986) Multicommodity, multimode freight transportation: A general modeling and algorithmic framework for the service network design problem. Transportation Research Part B: Methodological $20(3): 225-242$ 
Demir E, Bektaş T, Laporte G (2011) A comparative analysis of several vehicle emission models for road freight transportation. Transportation Research Part D: Transport and Environment 16(5):347-357

Department for Transport (2005) Truck specifications for best operational efficiency. Tech. rep., London

Department for Transport (2011) Transport statistics Great Britain 2011. Tech. rep., London

Department for Transport (2012) Transport statistics Great Britain 2012. Tech. rep., London

Ebery J, Krishnamoorthy M, Ernst A, Boland N (2000) The capacitated multiple allocation hub location problem: Formulations and algorithms. European Journal of Operational Research 120(3):614-631

Engau A, Wiecek MM (2007) Generating $\epsilon$-efficient solutions in multiobjective programming. European Journal of Operational Research 177(3):1566-1579

Faulkner D (2004) Shipping safety: a matter of concern. Proceedings of IMarEST-Part B-Journal of Marine Design and Operations 2004(5):37-56

Forkenbrock DJ (2001) Comparison of external costs of rail and truck freight transportation. Transportation Research Part A: Policy and Practice 35(4):321-337

Ghoseiri K, Szidarovszky F, Asgharpour MJ (2004) A multi-objective train scheduling model and solution. Transportation Research Part B: Methodological 38(10):927 - 952

Holmberg K, Yuan D (2000) A Lagrangian heuristic based branch-and-bound approach for the capacitated network design problem. Operations Research 48(3):461-481

Janic M (2007) Modelling the full costs of an intermodal and road freight transport network. Transportation Research Part D: Transport and Environment 12(1):33-44

Janic M, Bontekoning Y (2002) Intermodal freight transport in europe: an overview and prospective research agenda. Proceedings Focus Group 1:1-21

Kuby M, Xu Z, Xie X (2001) Railway network design with multiple project stages and time sequencing. Journal of Geographical Systems 3(1):25-47

Lane B (2006) Life cycle assessment of vehicle fuels and technologies. Tech. rep., Bristol UK

Macharis C, Bontekoning YM (2004) Opportunities for or in intermodal freight transport research: A review. European Journal of Operational Research $153(2): 400-416$

Magnanti TL, Wong RT (1984) Network design and transportation planning: Models and algorithms. Transportation Science 18(1):1-55

Mavrotas G (2009) Effective implementation of the $\epsilon$-constraint method in multi-objective mathematical programming problems. Applied Mathematics and Computation 213(2):455-465

McKinnon A, Piecyk M (2010) Measuring and managing $\mathrm{CO}_{2}$ emissions in european chemical transport. Heriot-Watt University, Edinburgh

Meng Q, Wang X (2011) Intermodal hub-and-spoke network design: Incorporating multiple stakeholders and multi-type containers. Transportation 
Research Part B: Methodological 45(4):724-742

Oliver J, Janssens-Maenhout G, Peters J (2012) Trends in global $\mathrm{CO}_{2}$ emissions: 2012 report. Tech. rep., Netherlands

Park D, Kim NS, Park H, Kim K (2012) Estimating trade-off among logistics cost, $\mathrm{CO}_{2}$ and time: A case study of container transportation systems in Korea. International Journal of Urban Sciences 16(1):85-98

Steenbrink PA (1974) Transport network optimization in the Dutch integral transportation study. Transportation Research 8(1):11-27

The World Bank (2012) Carbon finance unit. http://web.worldbank. org/WBSITE/EXTERNAL/TOPICS/ENVIRONMENT/EXTCARBONFINANCE/0, , contentMDK : $21848927 \sim$ menuPK : 4125939 pagePK : 64168445 piPK : 64168309 theSitePK: 4125853,00.html

Treitl S, Nolz P, Jammernegg W (2012) Incorporating environmental aspects in an inventory routing problem. a case study from the petrochemical industry. Flexible Services and Manufacturing Journal pp 1-27

Winebrake JJ, Corbett JJ, Falzarano A, Hawker JS, Korfmacher K, Ketha S, Zilora S (2008a) Assessing energy, environmental, and economic tradeoffs in intermodal freight transportation. Journal of the Air \& Waste Management Association 58(8):1004-1013

Winebrake JJ, Corbett JJ, Hawker JS, Korfmacher K (2008b) Intermodal freight transport in the great lakes: Development and application of a great lakes geographic intermodal freight transport model. Tech. rep., Rochester, US

Yamada T, Russ BF, Castro J, Taniguchi E (2009) Designing multimodal freight transport networks: a heuristic approach and applications. Transportation Science 43(2):129-143

Zografos KG, Regan AC (2004) Current challenges for intermodal freight transport and logistics in europe and the united states. Transportation Research Record: Journal of the Transportation Research Board 1873:70-78

\section{Appendix}

Table 13-15 list the capacity utilization for 3 transport modes when $f_{t}=£ 50$, $£ 100$ and $£ 150$ with 10 fold of commodities in Table 2 . 
Table 14 Comparison of capacity utilisation for 3 modes when $f_{t}=£ 50$ and demand is increased 10-fold

\begin{tabular}{|c|c|c|c|c|c|c|c|c|c|}
\hline \multicolumn{4}{|c|}{ Truck } & \multicolumn{3}{|c|}{ Rail } & \multicolumn{3}{|c|}{ Ship } \\
\hline & $\begin{array}{l}\text { Total } \\
\text { No. }\end{array}$ & $\begin{array}{l}\text { Total } \\
\text { tonnage }\end{array}$ & $\begin{array}{c}\text { Capacity } \\
\text { utilization }(\%)\end{array}$ & $\begin{array}{l}\text { Total } \\
\text { No. }\end{array}$ & $\begin{array}{l}\text { Total } \\
\text { tonnage }\end{array}$ & $\begin{array}{c}\text { Capacity } \\
\text { utilization }(\%)\end{array}$ & $\begin{array}{l}\text { Total } \\
\text { No. }\end{array}$ & $\begin{array}{l}\text { Total } \\
\text { tonnage }\end{array}$ & $\begin{array}{c}\text { Capacity } \\
\text { utilization }(\%)\end{array}$ \\
\hline 1 & 241 & 6970 & 99.73 & 207 & 79080 & 96.23 & 27 & 64370 & 80.27 \\
\hline 2 & 245 & 7105 & 100.00 & 210 & 80624 & 96.71 & 25 & 62629 & 84.35 \\
\hline 3 & 245 & 7105 & 100.00 & 211 & 80624 & 96.25 & 25 & 62614 & 84.33 \\
\hline 4 & 289 & 8365 & 99.81 & 199 & 77805 & 98.48 & 28 & 63427 & 76.27 \\
\hline 5 & 290 & 8380 & 99.64 & 200 & 77775 & 97.95 & 27 & 63355 & 79.01 \\
\hline 6 & 292 & 8437 & 99.63 & 199 & 77718 & 98.37 & 27 & 63298 & 78.94 \\
\hline 7 & 428 & 12370 & 99.66 & 188 & 73697 & 98.74 & 28 & 63120 & 75.90 \\
\hline 8 & 430 & 12428 & 99.66 & 188 & 73630 & 98.65 & 27 & 63064 & 78.64 \\
\hline 9 & 430 & 12443 & 99.78 & 188 & 73634 & 98.66 & 27 & 63092 & 78.68 \\
\hline
\end{tabular}

Table 15 Comparison of capacity utilisation for 3 modes when $f_{t}=£ 100$ and demand is increased 10-fold

\begin{tabular}{|c|c|c|c|c|c|c|c|c|c|}
\hline \multicolumn{4}{|c|}{ Truck } & \multicolumn{3}{|c|}{ Rail } & \multicolumn{3}{|c|}{ Ship } \\
\hline & $\begin{array}{l}\text { Total } \\
\text { No. }\end{array}$ & $\begin{array}{c}\text { Total } \\
\text { tonnage }\end{array}$ & $\begin{array}{c}\text { Capacity } \\
\text { utilization( }(\%)\end{array}$ & $\begin{array}{l}\text { Total } \\
\text { No. }\end{array}$ & $\begin{array}{c}\text { Total } \\
\text { tonnage }\end{array}$ & $\begin{array}{c}\text { Capacity } \\
\text { utilization(\%) }\end{array}$ & $\begin{array}{l}\text { Total } \\
\text { No. }\end{array}$ & $\begin{array}{l}\text { Total } \\
\text { tonnage }\end{array}$ & $\begin{array}{c}\text { Capacity } \\
\text { utilization }(\%)\end{array}$ \\
\hline 1 & 0 & 0 & $\mathrm{~N} / \mathrm{A}$ & 225 & 86050 & 96.33 & 28 & 65670 & 78.97 \\
\hline 2 & 0 & 0 & $\mathrm{~N} / \mathrm{A}$ & 229 & 87638 & 96.40 & 26 & 64100 & 83.01 \\
\hline 3 & 0 & 0 & $\mathrm{~N} / \mathrm{A}$ & 229 & 87638 & 96.40 & 24 & 63042 & 88.44 \\
\hline 4 & 10 & 279 & 96.21 & 220 & 85773 & 98.21 & 29 & 65583 & 76.14 \\
\hline 5 & 11 & 308 & 96.55 & 220 & 85767 & 98.20 & 27 & 65211 & 81.32 \\
\hline 6 & 10 & 279 & 96.21 & 221 & 85796 & 97.79 & 26 & 64625 & 83.69 \\
\hline 7 & 22 & 627 & 98.28 & 217 & 85429 & 99.16 & 29 & 65671 & 76.25 \\
\hline 8 & 39 & 1119 & 98.94 & 216 & 84935 & 99.05 & 27 & 65122 & 81.21 \\
\hline 9 & 39 & 1119 & 98.94 & 216 & 84935 & 99.05 & 27 & 65122 & 81.21 \\
\hline
\end{tabular}

Table 16 Comparison of capacity utilisation for 3 modes when $f_{t}=£ 150$ and demand is increased 10-fold

\begin{tabular}{|c|c|c|c|c|c|c|c|c|c|}
\hline \multicolumn{4}{|c|}{ Truck } & \multicolumn{3}{|c|}{ Rail } & \multicolumn{3}{|c|}{ Ship } \\
\hline & $\begin{array}{l}\text { Total } \\
\text { No. }\end{array}$ & $\begin{array}{c}\text { Total } \\
\text { tonnage }\end{array}$ & $\begin{array}{c}\text { Capacity } \\
\text { utilization }(\%)\end{array}$ & $\begin{array}{l}\text { Total } \\
\text { No. }\end{array}$ & $\begin{array}{c}\text { Total } \\
\text { tonnage }\end{array}$ & $\begin{array}{c}\text { Capacity } \\
\text { utilization(\%) }\end{array}$ & $\begin{array}{l}\text { Total } \\
\text { No. }\end{array}$ & $\begin{array}{l}\text { Total } \\
\text { tonnage }\end{array}$ & $\begin{array}{c}\text { Capacity } \\
\text { utilization(\%) }\end{array}$ \\
\hline 1 & 0 & 0 & $\mathrm{~N} / \mathrm{A}$ & 225 & 86050 & 96.33 & 28 & 65670 & 78.97 \\
\hline 2 & 0 & 0 & $\mathrm{~N} / \mathrm{A}$ & 229 & 87638 & 96.40 & 24 & 63042 & 88.44 \\
\hline 3 & 0 & 0 & $\mathrm{~N} / \mathrm{A}$ & 229 & 87638 & 96.40 & 24 & 63042 & 88.44 \\
\hline 4 & 5 & 134 & 92.41 & 220 & 86028 & 98.50 & 29 & 65865 & 76.47 \\
\hline 5 & 12 & 337 & 96.84 & 219 & 85738 & 98.61 & 27 & 65324 & 81.46 \\
\hline 6 & 5 & 134 & 92.41 & 220 & 86028 & 98.50 & 26 & 64530 & 83.57 \\
\hline 7 & 15 & 424 & 97.47 & 217 & 85325 & 99.04 & 29 & 66285 & 76.96 \\
\hline 8 & 16 & 453 & 97.63 & 217 & 85294 & 99.01 & 27 & 65919 & 82.20 \\
\hline 9 & 16 & 453 & 97.63 & 217 & 85294 & 99.01 & 26 & 65125 & 84.34 \\
\hline
\end{tabular}

